\title{
PREDICTION OF STATURE BASED ON FOOT LENGTH IN MEDICAL STUDENTS OF BIRAT MEDICAL COLLEGE \& TEACHING HOSPITAL, MORANG, NEPAL
}

\author{
Mehta $U K^{1^{*}}$, Dhakal $A^{1}$, Parajuli $S B^{2}$, Shah $S^{1}$
}

\section{Affiliation}

1. Lecturer, Department of Anatomy, Birat Medical College \& Teaching Hospital, Morang, Nepal

2. Assistant Professor, Department of Community Medicine, Birat Medical College \& Teaching Hospital, Morang, Nepal

\section{ARTICLE INFO \\ Article History \\ Received : 20 June, 2019 \\ Accepted : 02 August, 2019 \\ Published : 31 August, 2019}

(C) Authors retain copyright and grant the journal right of first publication with the work simultaneously licensed under Creative Commons Attribution License CC - BY 4.0 that allows others to share the work with an acknowledgment of the work's authorship and initial publication in this journal.

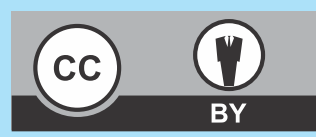

ORA 118

DOI: http://dx.doi.org/10.3126/bjhs.v4i2.25441

* Corresponding Author

Mr. Umesh Kumar Mehta Lecturer

Department of Anatomy

Birat Medical College \& Teaching Hospital Morang, Nepal

Email ID: ukmehta32@gmail.com

ORCID ID: https://orcid.org/0000-0003-3095-8415

\section{Citation}

Mehta UK, Dhakal A, Parajuli SB, Shah S. Prediction of Stature Based on Foot Length in Medical Students of Birat Medical College \& Teaching Hospital, Morang, Nepal. BJHS 2019;4(2)9: 707-711.

\section{ABSTRACT}

\section{Introduction}

Stature is one of the most important anatomical parameters for personal identification. Estimation of stature by measuring different parts of the body is valuable in medico legal investigations as well as in anthropology.

\section{Objectives}

The objective of this study was to find correlation between stature and foot length and developing a regression equation for stature estimation from foot length among medical students of Birat Medical College \& Teaching Hospital, Morang, Nepal.

\section{Methodology}

This is cross sectional study conducted at Department of Anatomy of Birat Medical College \& Teaching Hospital, Morang, Nepal from 15 March 2019 to 15 June 2019. Two hundred (100 male and 100 female) medical students were enrolled in the study. Stature and foot length were measured using standard instruments. The collected data was entered into Microsoft excel and analyzed by using SPSS.

\section{Results}

The mean stature in male was $165.4 \mathrm{~cm}$ with SD of $8.46 \mathrm{~cm}$, in female the mean stature was $156.5 \mathrm{~cm}$ and with SD $6.56 \mathrm{~cm}$. The mean foot length in male was $25.84 \mathrm{~cm}$ with SD of $1.73 \mathrm{~cm}$, in female mean foot length was $23.35 \mathrm{~cm}$ with SD $1.30 \mathrm{~cm}$. This gender wise difference in mean stature and foot length between males and females was statistically significant $(p<0.001)$. There was significant positive correlation between stature and foot length $(r=0.534, P<0.001)$ for male and $(r=0.675, P<0.001)$ for female. Regression equations were derived for estimation of stature from measurement of foot length in both sexes.

\section{Conclusion}

This research found significant positive correlation between stature and foot length in both sexes. Regression equation was also derived which help to predict the stature by knowing the foot length in medico legal cases.

\section{KEY WORDS}

Correlation coefficient, foot length, regression equation, stature 


\section{INTRODUCTION}

Stature or body height is one of the most important parameters for personal identification. ${ }^{1}$

In forensic anthropology various parameters such as age, sex, ethnicity, stature etc. are used for personal identification. Among these, stature estimation is an essential element in the identification of an individual. ${ }^{2}$ It is usually measured as standing height of the individual but assessment of stature is difficult when dead bodies are mutilated, burnt or skeletonised. ${ }^{3-4}$

Establishing an individual's identity from mutilated, decomposed and amputated body fragments has become an important necessity in recent times due to natural disasters such as earthquakes, tsunamis, cyclones, floods and man-made disasters such as terrorist attacks, bomb blasts, massive accidents, wars, air accidents, etc. It is important for both legal and humanitarian reasons. ${ }^{5}$

The forensic scientists are well aware of the fact that the complete skeleton is rarely available at the scene of crime. Thus the researchers may have no way out than to utilize numerical technique for stature recreation. This is of obvious advantage that it is workable even if a part of upper or lower extremity is available for examination. ${ }^{6}$

Estimation of stature from measurements of upper limb and lower limb bones has been attempted by many scientists with varying degree of accuracy. It has been shown that the reliability of prediction of height from foot measurements was as high as that from long bones. ${ }^{8}$

Ossification and maturation in the foot occurs earlier than the long bones and therefore, during adolescence age, height could be more accurately predicted from foot measurement as compared to that from long bones. ${ }^{9}$ Various studies in the past have been undertaken to study the relation between height and various body parts but not much has been done to derive it from the foot length. Therefore, the study was conducted with the objective to find correlation between stature and foot length and developing a regression equation for stature estimation from foot length among medical students of Birat Medical College \& Teaching Hospital, Morang, Nepal.

\section{METHODOLOGY}

This is cross sectional study conducted at Department of Anatomy of Birat Medical College \& Teaching Hospital, Morang, Nepal from 15 March 2019 to 15 June 2019. Two hundred (100 male and 100 female) medical students representing all batches currently studying in the institute were enrolled in the study. The convenient sampling technique was used to enrol the students. All the students were Nepali origin. Ethical clearance was obtained from the IRC (Ref: IRC-PA-020/2075-76)Birat Medical College \& Teaching Hospital. Informed consent of participants was taken. The socio-demographic variables like age and sex were noted. The participants having any disease, deformity, injury, fracture or record of any surgical procedures were not included in the study. During the study period students who did not consent or not available were also excluded.

The height of the individual was measured between the vertex and floor, with the person standing erect, in anatomical position and the head in the Frankfort plane, using a standing height measuring instrument in centimeter. The left foot was selected for measurement as per recommendation of the international agreement for paired measurements at Geneva (1912). ${ }^{10}$ Foot length was measured as a direct distance from the most prominent point of the back of the heel to the tip of the hallux or to the tip of second toe when the second toe was longer than hallux by spreading caliper in centimetre (figure 1).This measurement excluded any nail that extends beyond the end of the toe.

A small group of students were taken for measurements each day at a fixed time between (11:00 am to 2:00 pm)to avoid diurnal variation and single observer conducted the measurements. The data obtained were entered in MS excel and analysed by SPSS (Statistical package for Social Sciences). The $t$ test and Pearson Correlation was used to calculate $p$ value.

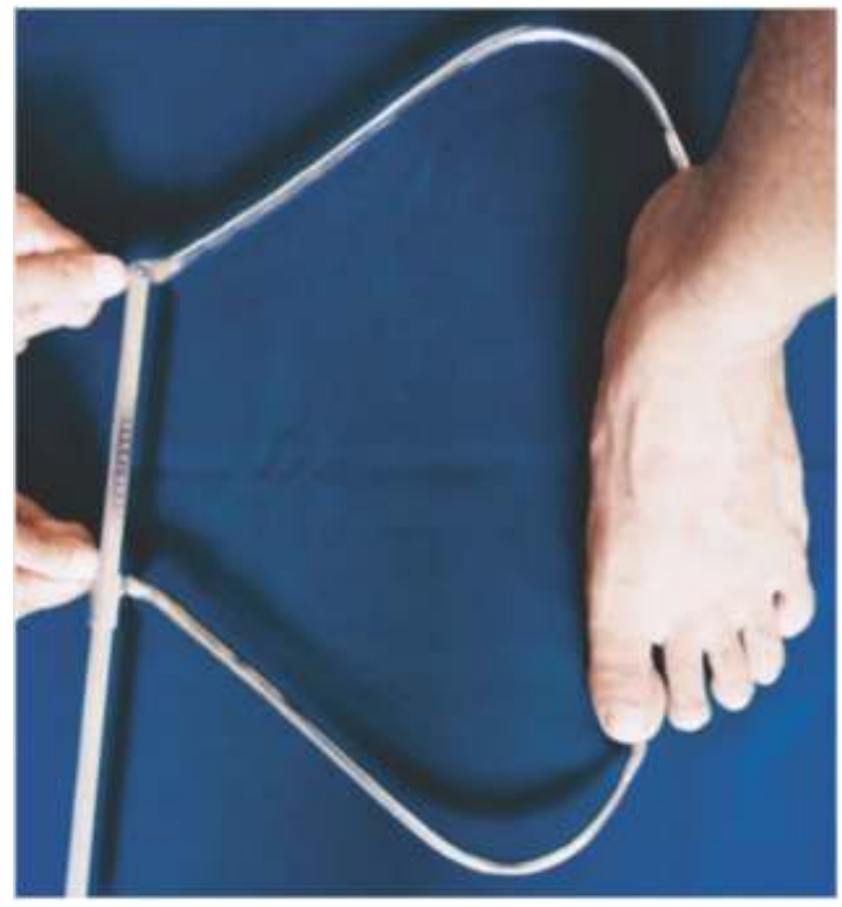

Figure 1: Measurement of foot length

\section{RESULTS}

A total 100 males and 100 females were included in the study. The study group included the individuals aged between $18-25$ years. Stature in male varied from $135 \mathrm{~cm}$ to $180 \mathrm{~cm}$ with mean value of $165.4 \mathrm{~cm}$ and standard deviation (SD) of $8.46 \mathrm{~cm}$. Stature in female varied from 142 $\mathrm{cm}$ to $170 \mathrm{~cm}$ with mean value of $156.5 \mathrm{~cm}$ and standard deviation (SD) of $6.56 \mathrm{~cm}$ (Table 1). This gender wise difference in mean stature between males and females was statistically significant $(p<0.001)$. Thus, a male student was likely to be taller than a female student. 


$\begin{array}{lcc}\begin{array}{l}\text { Table 1: Stature in both males and females } \\ \text { Parameters }\end{array} & \text { Male } & \text { Female } \\ \text { Total Number } & 100 & 100 \\ \text { Stature range }(\mathrm{cm}) & 135-180 & 142-170 \\ \text { Mean stature }(\mathrm{cm}) & 165.4^{*} & 156.5 \\ \text { Standard deviation of height } & 8.46 & 6.56\end{array}$

*= statistically significant ( $p$-Value $<0.001)$

Foot length in male varied from $19.5 \mathrm{~cm}$ to $28.8 \mathrm{~cm}$ with mean value of $25.84 \mathrm{~cm}$ and standard deviation (SD) of 1.73 $\mathrm{cm}$. Foot length in female varied from $20 \mathrm{~cm}$ to $26.5 \mathrm{~cm}$ with mean value and standard deviation of $23.35 \mathrm{~cm}$ and $1.30 \mathrm{~cm}$ respectively (table2). This gender wise difference in mean foot length between males and females was statistically significant $(p<0.001)$. Thus, the foot length of a male student was likely to be greater than that of a female student.

Table 2: Foot length in both males and females

$\begin{array}{lcc}\text { Parameters } & \text { Male } & \text { Female } \\ \text { Total Number } & 100 & 100 \\ \text { Foot length range }(\mathrm{cm}) & 19.5-28.8 & 20-26.5 \\ \begin{array}{l}\text { Mean foot length }(\mathrm{cm}) \\ \text { Standard deviation of }\end{array} & 25.84^{*} & 23.35 \\ \text { foot length } & 1.73 & 1.30\end{array}$

*= statistically significant ( $p$-Value < 0.001)

Correlation coefficient between stature and foot length was studied with Pearson Correlation analysis. There is significant correlation coefficient between stature and foot length $(r=0.534, P<0.001)$ for male and $(r=0.675, P<0.001)$ for female (table 3 ). It means that there is positive correlation between stature and foot length. Visual representation of those relationships is presented in figure $2 \& 3$. Regression equations were derived for estimation of stature from foot length shown in table 4.

Table 3: Correlation coefficient ( $r$ ), regression coefficient (b) and value of constant (a) in Males and Females

$\begin{array}{lccc}\text { Values } & \text { Male } & \text { Female } & \text { p-Value } \\ \begin{array}{l}\text { Correlation Coefficient (r) } \\ \text { (Stature and Foot length) }\end{array} & 0.534 & 0.675 & <0.001 \\ \begin{array}{l}\text { Regression Coefficient (b) } \\ \text { (Stature and Foot length) }\end{array} & 2.60 & 3.40 & \\ \begin{array}{l}\text { Value of Constant (a) } \\ \text { (Stature and Foot length) }\end{array} & 98.10 & 76.99 & \end{array}$

Table 4: Derivation of regression equation for both sexes

$\begin{array}{ll}\text { Male } & Y(\mathrm{~cm})=2.60 X+98.10 \\ \text { Female } & Y(\mathrm{~cm})=3.40 X+76.99 \\ & Y=\text { Stature } X=\text { Foot length }\end{array}$

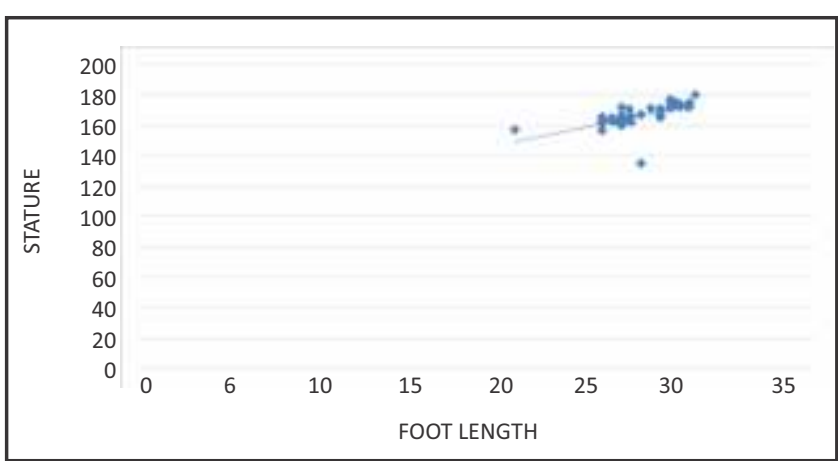

Figure 1: Scatter diagram showing correlation between foot length and stature in Male (cm)

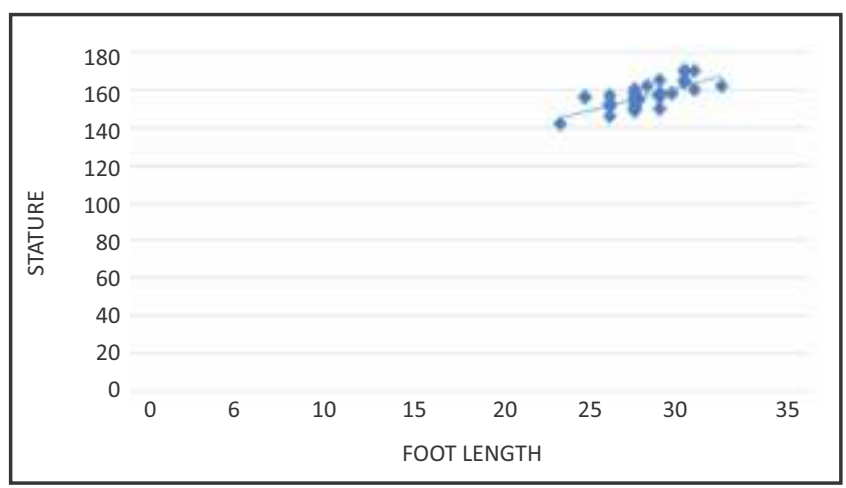

Figure 3: Scatter diagram showing correlation between foot length and stature in Female $(\mathrm{cm})$

\section{DISCUSSION}

Stature estimation is considered as one of the important parameters in identification of a person. The body parts show biological correlation with stature. Several studies have been conducted on the estimation of stature from body parts or skeletal remains., 3, 5, 7 There are several methods to estimate stature from the bones but the simplest and most reliable method is by regression analysis. This study showed that the mean stature of male was 165.4 $\pm 8.46 \mathrm{~cm}$ and that of female was $156.5 \pm 6.56 \mathrm{~cm}$ with a statistically significant difference $(p<0.001)$. We also found out that the mean foot length of male was $25.84 \pm 1.73 \mathrm{~cm}$ and that of female was $23.35 \pm 1.30 \mathrm{~cm}$ which was statistically significant difference $(p<0.001)$. Similarly, statistically significant positive correlation $(r=0.534$, $P<0.001)$ for male and $(r=0.675, P<0.001)$ for female was found between the stature and the length of foot. The correlation coefficients between the stature and the length of the foot indicate that the length of the foot provides greater reliability and precision in estimating the stature of an unknown individual. ${ }^{11}$ Parekh $U$ et al. revealed mean value of stature was greater for males than female with statistically significant difference. ${ }^{12}$ Similarly; mean value of foot length was significantly greater for males. Our findings were also same as the observation of Parekh $U$ et al. These results also correlate with the study conducted by Krishan $\mathrm{K}$ et al. in North Indian population and Sanil SG et al. and Ozdan $\mathrm{H}$ et al. with Turkish population. ${ }^{11,13,14}$ The differences in stature and foot measurement in males and females can be attributed to the fact that fusion of epiphyses of bones 
occurs earlier in females and later in males. Another factor may be a taller and narrower pelvis in men that makes them taller than women. This study showed that males were likely to be taller as compared to females. In our study we measured only the left foot as per the recommendation for paired measurements. ${ }^{10}$ But studies conducted by Gulsah et al, K. Kewal et al and Robbins LM have not shown any statistically significant side differences. ${ }^{15-17}$ Robbins in her study suggested that either of the foot could be used for estimation of height. ${ }^{17}$ Rameswarapu SB et al. studied the estimation of stature from foot length among 104 healthy individuals (54 males \& 50 females) of Secunderabad population, India. ${ }^{18}$ The study showed positive correlation coefficient between stature and foot length which was significant. Gulash et al. conducted a study to estimate height and sex through foot measurements in 249 adults ( 136 men and 113 women) aged between 18 and 44 , born in Turkey. ${ }^{15}$ They found that the highest correlation to be present between foot length and stature than between other foot measurements and stature. Jakhar JK et al. conducted study in the Department of Forensic Medicine and Toxicology of the State of Haryana. ${ }^{19}$ A total of 103 medical students were included which showed a good height correlation with the foot length and were statistically very significant. Ilayperuma I et al. carried out a study on 210 medical students of the faculty of Medicine, University of Ruhuna, Sri Lanka. They showed positive correlation coefficient between stature and foot length which was statistically significant. ${ }^{20}$ Sen et al. studied the foot measurements and stature of 350 Rajbanshis of West Bengal (175 males and 175 females) and derived different formulae to reconstruct height from these measurements. ${ }^{21}$ Kanchana et al. studied the relationship between stature and foot dimension among 200 (100 males and 100 females) Gujjars, an endogamous group from Northern India. ${ }^{22}$ They derived multiplication factor and regression equation from foot dimension to estimate stature. Mohanty $B B$ and Agrawal D et al. conducted a study on population of Odisha, developed a regression equation that could calculate an individual's height from the length of foot showing as height increases, foot length of both male and female also increases. ${ }^{23}$ Qamra et al. derived a regression equation between foot and height in North West Indian population demonstrating strong positive correlation with correlation coefficient of 0.69 for males and 0.70 for females. ${ }^{24}$ Similar conclusion was drawn by Patel SM et al. in Gujrat population, Mansur DI et al. in Nepalese population and Patil GV et al. in south Indian population. ${ }^{9,26}$ In Present study we also derived regression equation between stature

\section{REFERENCES}

1. K. Krishan, T. Kanchan, R.G. Menezes, A. Ghosh. Forensic anthropology casework-ssential methodological considerations in stature estimation. J Forensic Nurs. 2012:45-50. DOI: 10.1111/j. 19393938. 2011.01122.x

2. Sen J, Kanchan T, Ghosh A, Mondal N, Krishan K. Estimation of stature from lengths of index and ring fingers in a North-eastern Indian population. J Forensic Leg Med 2014; 22:10-5. DOI: 10.1016/ j.jflm.2013.11.010 and foot length with the correlation coefficients between stature and foot length is +0.53 for male and +0.67 for female which is most significant. It means there is a strong relation between stature and foot length. If either of the measurement (foot length or total height) is known the other can be calculated and this would be helpful for Anthropologists and Forensic Medicine specialists.

\section{CONCLUSION}

This research found significant positive correlation between stature and foot length in both sex. Regression equation was also derived which help to predict the stature by knowing the foot length in medico legal cases.

\section{RECOMMENDATIONS}

The number of participants included in this study is limited to a single medical college. It is recommended that incorporating data of similar studies done in various region of the country would provide significant conclusion regarding the subject discussed.

\section{LIMITATION OF THE STUDY}

In this study, we measured only the left foot as per the recommendation for paired measurements. Broader understanding of the subject could have been obtained if both feet have been measured and the differences in the predicted stature of each were compared. Also, single observer could have limited this study in terms of differences in measurement that may have occurred.

\section{ACKNOWLEDGEMENT}

The authors would like to acknowledge all participants for their support, time and participation, without whom this study would not have been possible. The authors would also like to thank Dr. Rajesh Kumar Shah, Department of Forensic medicine and the Institutional Review Committee of Birat Medical College \& Teaching Hospital, Morang, Nepal for their support and cooperation.

\section{CONFLICT OF INTEREST}

The authors would like to declare no conflict of interest.

\section{FINANCIALDISCLOSURE}

There are no financial conflicts of interest to disclose.

3. Trotter M, Gleser GC. Estimation of stature from long bones of American Whites and Negroes. The Am J PhysAnthropol. 1952; 10: 463-514. PMID:13007782

4. Trotter M and Gleser GC. A re-evaluation of estimation of stature based on measurements of stature taken during life and of long bones after death. The Am J of Phys Anthrop.1958; 16: 79-123. PMID:13571400

5. Chikhalkar BG, Mangaonkar AA, Nanandkar SD, Peddawad RG. Estimation of Stature from Measurements of Long Bones, Hand and Foot Dimensions. J Indian Acad Forensic Med. 2010; 32(4) 329-33. ISSN: 0971-0973 
6. Bhavna, Nath S. Use of Lower Limb Measurements in Reconstructing Stature among Shia Muslims. Internet Journal of Biological Anthropology.2009; 2(2):86-97.

7. Athwale MC. Estimation of height from lengths of forearm bones. A study of one hundred Maharashtrian male adults of ages between twenty five and thirty years. American Journal of Physical Anthropology.1963; 21:105-12. DOI:10.1002/ajpa.1330210203

8. Rutishauser IHE. Prediction of Height from Foot Length: Use of Measurement in Field Surveys. 1968; 43: 310-15. DOI: 10.1136/adc. 43.229.310

9. Patel SM, Shah GV, Patel SV. Estimation of height from measurements of foot length in Gujarat region. J AnatSoc India. 2007; 56(1): 25-27.

10. Maccurdy GG. International Congress of Prehistoric Anthropology and Archeology, Geneva. American Anthropolgist. 1912; 14(4):621631. DOI: 10.1525/aa.1912.14.4.02a00050

11. Krishnan K, Sharma A. Estimation of stature from dimensions of hands and feet in a North Indian population. Journal of Forensic and Legal Medicine. 2007; 14(6):327-332. DOI: 10.1016/j.jcfm.2006.10.008

12. Parekh U, Patel R, Patel P. A Study of Relation of Stature with Foot Length in Natives of Gujarat State. NHL Journal of Medical Sciences Jan 2014; 3 (1):22-25.

13. Sanli SG, Kizilkanat ED, Boyan N, Ozsahin ET, Bozkir MG, Soames R, et al. Stature estimation based on hand length and foot length. Clin Anat. 2005; 18(8):589-596. DOI:10.1002/ca.20146

14. Ozden H, Balci Y, Demirüstü C, Turgut A, Ertugrul M. Stature and sex estimate using foot and shoe dimensions. Forensic Sci Int. 2005; 147(2-3):181-184. DOI: 10.1016/j.forsciint.2004.09.072

15. Zeybek G, Ergur I, Demiroglu Z. Stature and gender estimation using foot measurements. Forensic Sci Int. 2008;181(1-3):54.e1-5. DOI: 10.1016/j.forsciint.2008.08.003

16. K. Kewal\&S.abhilasha. Estimation of stature from dimensions of hands and feet in a North Indian population. Journal of Forensic and Legal Medicine 2007; 327-332. DOI: 10.1016/j.jcfm.2006.10.008
17. Robbins LM. Estimating Height and Weight from size of Footprints. J Forensic Sci 1986;31(1):143-52. PMID: 3944558

18. SB Rameswarapu, Deepika. V, Potturi.Br. Estimation of Stature from Foot Length. IJPBS 2013;3(3):266-70.

19. Jakhar JK, Pal V, Paliwal PK. Estimation of Height from Measurements of Foot Length in Haryana Region. J Indian Acad Forensic Med, 32(3). ISSN 0971-0973

20. Ilayperuma I et al. A model for reconstruction of personal stature based on the measurements of foot length. Galle Medical Journal 2008; 13(1): 6-9. DOI: 10.4038/gmj.v13i1.885

21. Sen J, Ghosh S. Estimation of stature from footlength and foot breadth among the Rajbanshi: an indigenous population of North Bengal. Forensic Scilnt 2008; 181:55e1-55e6.Forensic Sci Int. 2008; 181 (1-3):55.e1-6. DOI: 10.1016/j.forsciint.2008.08.009.

22. Kanchan T, Menezes RG, Moudgil R, Kaur R, Kotian MS, K Rakesh Garg. Stature estimation from foot dimensions. Forensic Scilnt 2008; 179 (2-3):241.e1-241e.5. DOI: 10.1016/j.forsciint.2008.04.029.

23. Mohanty BB, Agrawal D, Mishra K, Samanthsinghar P, Chinara PK. Estimation of height of an individual from foot length. A Study on population of odisha. Int J Rev Life Sci 2012;2(2):69-74. ISSN: 22312935

24. Qamra S, Jit I, Deodhar SD. A model for reconstruction of height from foot measurements in a adult population of Northwest India. Indian J Med Res 1980; 71:77-83. PMID: 7380514

25. Mansur DI, Haque MK, Sharma K, Karki R K, Khanal K, Karna R. Estimation of Stature from Foot Length in Adult Nepalese Population and its Clinical Relevance. KUMJ 2012; 10(1):16-19. PMID: 22971855

26. Patil GV, Kumar S. A study of relation of stature with foot length in first year medical students of south Indian origin. 2014;6(8):7872-7873. ISSN: 0975-833X 